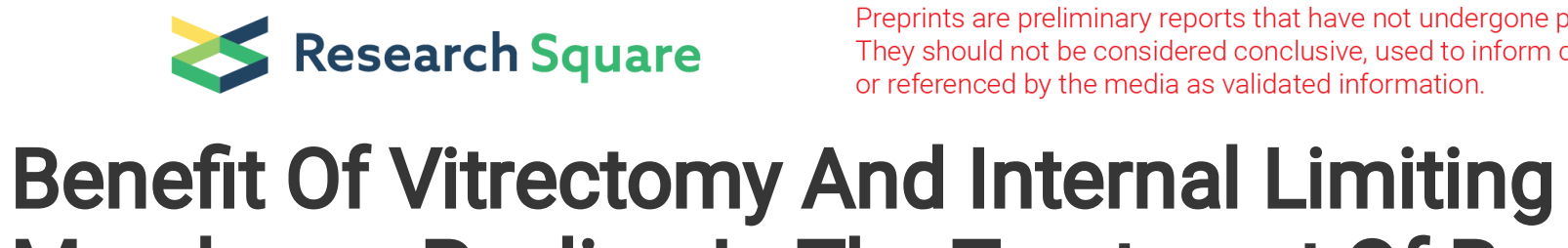 \\ Membrane Peeling In The Treatment Of Resistant Diabetic Macular Edema
}

Ahmet Altun ( $\square$ aaltun06@gmail.com )

Bahçeşehir University

Fatih Atmaca

Istinye University

Hatice Selen Kanar

Dr Lütfı Kırdar Kartal Eğitim ve Araştırma Hastanesi

Aysu Karatay Arsan

Dr Lütfı Kırdar Kartal Eğitim ve Araştırma Hastanesi

Aynur Hacisalihoglu

Dr Lütfı Kırdar Kartal Eğitim ve Araştırma Hastanesi

\section{Banu Kale}

Medical Park Hospitals

\section{Turgay Ozay}

Medical Park Hospitals

Ali Durdu

Medical Park Hospitals

Kenan Sonmez

Medical Park Hospitals

\section{Research Article}

Keywords: diabetic macular edema (DME), vitrectomy, internal limiting membrane (ILM)

Posted Date: April 2nd, 2021

DOI: https://doi.org/10.21203/rs.3.rs-264766/v1

License: (1) (i) This work is licensed under a Creative Commons Attribution 4.0 International License.

Read Full License 


\section{Abstract}

Background: To investigate the results of internal limiting membrane (ILM) peeling in patients with resistant diabetic macular edema (DME).

Methods: In this randomized, controlled and prospective clinical study, the patients with resistant DME due to proliferative diabetic retinopathy were divided into two groups. Both groups underwent 23 gauge pars plana vitrectomy (PPV). Additionally ILM peeling was performed only to the cases in Group 2. During follow-ups, complete ophthalmological examinations, optical coherence tomography and fundus fluorescein angiography were performed. After PPV, intravitreal dexamethasone implant injection was performed for DME treatment when necessary. The patients were followed for 1 year.

Results: A total of 40 eyes of 37 patients were included in the study. The average age was $57.5 \pm 5.4$ and $56.9 \pm 5.8$ years, and the ratio of male:female was 9:11 and 6:14 in Group 1 and Group 2, respectively (p $>0.05$ ). The improvement level in BCVA was more evident especially in the first and third months postoperatively in both groups $(p<0.01)$. Improvement in BCVA in the first and third months postoperatively was statistically more significant in Group 2 than Group $1(p<0.05)$

\section{Conclusion:}

PPV is beneficial in the management of resistant DME, and ILM peeling seems to be useful for macular function and may accelerate improvement in visual acuity.

\section{Background}

The internal limiting membrane (ILM) is the structural border between the neurosensory retina and the vitreous body, formed by the footplates of Müller cells, and its thickness is 1,5 $\mu \mathrm{m}$ in peripheral fovea (1). It is postulated that this translucent membrane serves many basic essential functions such as a landing stage for the proliferation of myofibroblasts, fibrocytes and retinal pigment epithelial cells (2).

ILM peeling was first performed for macular hole surgery in 1996 to ensure complete removal of all possible tangential tractional components (3). With surgical removal, it was thought that the scaffolding task created by ILM would be eliminated for cellular proliferation that may occur later on the anterior surface of retina (4). Although the positive effects of ILM peeling on the anatomical and functional structure of the macula have not been proven, today it is frequently performed by most vitreoretinal surgeons during macula surgery including diabetic macular edema (5-8).

Although there are many studies in the literature claiming that ILM peeling is beneficial in the presence of vitreomacular traction (VMT) in patients with diabetic retinopathy, the benefit of performing this procedure in the absence of VMT is controversial (9-16). There are some randomized studies demostrated that ILM peeling had unfavourable outcomes, such as statistically significant absolute 
microscotomas within the central retinal area (17). In this clinical study, we aimed to investigate the effect of ILM peeling on the prognosis and management of resistant diabetic macular edema (DME).

\section{Methods}

This prospective and randomized study was approved by the Institutional Ethics Committee of University of Health Sciences, Turkey (Study number: 17073117-050.99-2786) and was organized and carried out in accordance with the principles and recommendations of the Helsinki Declaration. Informed consent was obtained from all patients who participated in the study. Patients who applied to our clinic between January 2018 and January 2020 who underwent pars plana vitrectomy (PPV) for resistant DME were included in this study. The cases were divided into two groups. ILM peeling was applied to patients in Group2, but not to Group 1.

Cataract surgery was made by phacoemulsification technique 3 weeks before vitreoretinal surgery. Threepiece acrylic hydrophobic monofocal intraocular lens (Acrysof, MA60AC, Alcon, USA) was implanted into the bag in cataract surgery. Cases that developed important complication (posterior capsule rupture, vitreus loss, lens dislocation) during cataract surgery were not included in the study. Cases with epiretinal membrane, vitreomacular traction, macular ischemia, intense vitreous hemorrhage, retinal detachment, previous macular laser treatment, type I diabetes mellitus, glaucoma, amblyopia, corneal pathology, uveitis and history of intraocular surgery were excluded from the study.

Resistant DME was defined as the minimal improvement in central retinal thickness $(<15 \%)$ to at least 4 treatments (three of which were anti-VEGF injection) in last 6 months (18). The same ophthalmologist (AA) performed all vitreoretinal operations and at least 2 retina specialist evaluated whole fundus fluorescein angiography (FFA) and optical coherence tomography (OCT) images. All cases received intravitreal anti-VEGF (Lucentis) drug injection 3 days before PPV operation. The missed panretinal photocoagulation procedure was completed in all cases during the vitreoretinal surgery that made under retrobulbar anesthesia with same machine (Constellation, Alcon, USA). ILM was dyed with brillant blue G (BBG) to increase visibility in eyes in Group 1. BBG with the concentration of $0.05 \mathrm{mg} / \mathrm{mL}$ (19) was applied for 2 seconds on macula. During macula surgery, the illumination power of microscope and endoillumination were set to $100 \%$ and $45 \%$, respectively.

During the follow-up period intravitreal dexamethasone (IVD) implant (Ozurdex®, Allergan Inc, Irvine, CA, USA) injection was performed for the management of resistant DME. The patients were followed up for 1 year. During follow-ups, complete ophthalmological examinations, OCT and FFA were performed, the need for additional intravitreal injection was noted.

The distribution of variables was measured by Kolmogorov simirnov test. In the analysis of quantitative independent data, Mann-Whitney $U$ test was used. Wilcoxon test was used to analyze dependent quantitative data. Chi-square test was used in the analysis of qualitative independent data. SPSS 26.0 program was used in the analysis and significance level was set at less than 0.05 . 


\section{Results}

A total of 40 eyes of 37 patients were included in the study. All patients had Caucasian ethnicity. There were 20 eyes of 18 patients in Group1, and 20 eyes of 19 patients in Group 2. The average age was 57.5 \pm 5.4 and $56.9 \pm 5.8$ years, and the ratio of male:female was 9:11 and 6:14 in Group 1 and Group 2, respectively. All patients were individuals with type II diabetes melllitus disease and Caucasian race. There were no significant differences between the groups in terms of age and gender $(p>0.05)($ Table 1$)$.

Table 1

Demographic characteristics of patients in groups

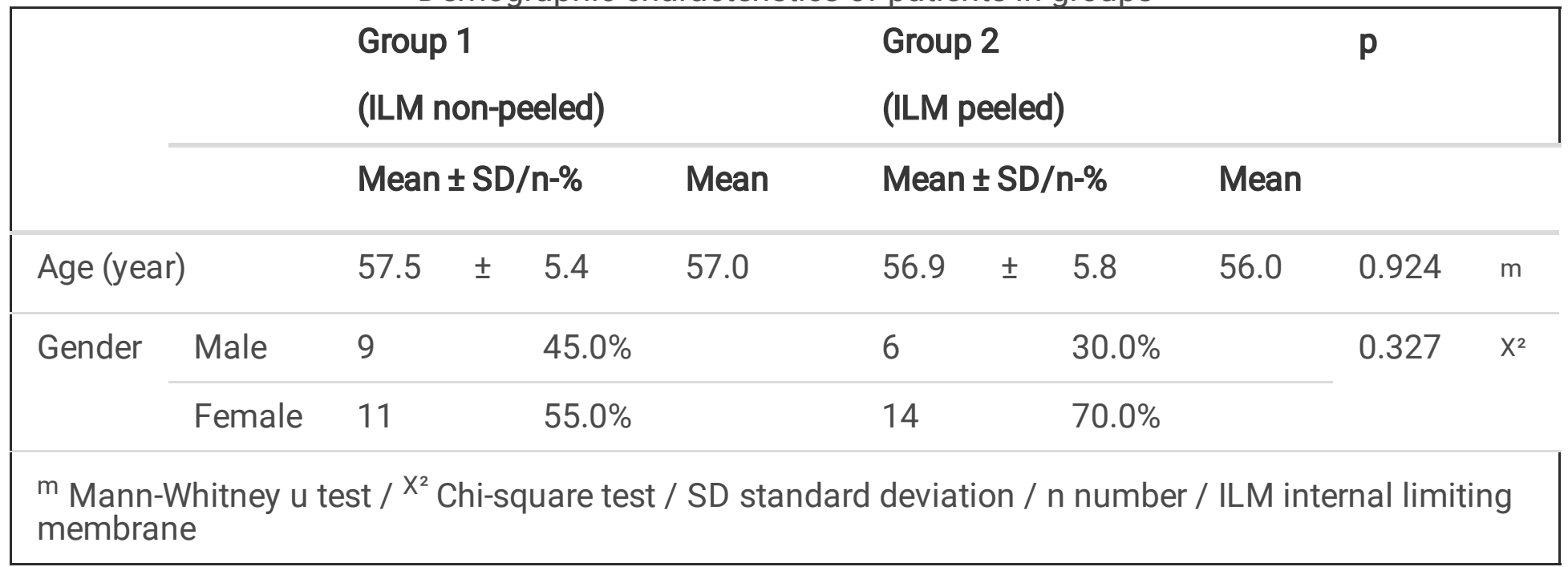

The mean number of intravitreal anti-VEGF injections before PPV was $3.85 \pm 0.81$ and $4.00 \pm 0.86$ in Group 1 and Group 2, respectively. The mean number of IVD implant injections before PPV was $1.25 \pm$ 0.79 and $1.35 \pm 0.67$ in Group 1 and Group 2, respectively. There was no statistically significant difference between the mean number of anti-VEGF and IVD implant injections before PPV $(p>0.05)$. The mean number of IVD implant injections needed in the postoperative period was $0.55 \pm 0.69$ and $0.10 \pm 0.31$ in Group 1 and Group 2, respectively, and that was statistically significantly lower in Group $2(p<0.05)$ (Table 2). 
Table 2

The number of intravitreal drug injections to groups

\begin{tabular}{|c|c|c|c|c|c|c|c|c|c|c|}
\hline \multirow{3}{*}{$\begin{array}{l}\text { Before PPV anti-VEGF } \\
\text { (n) }\end{array}$} & \multicolumn{4}{|c|}{$\begin{array}{l}\text { Group } 1 \\
\text { (ILM non-peeled) }\end{array}$} & \multicolumn{4}{|c|}{$\begin{array}{l}\text { Group } 2 \\
\text { (ILM peeled) }\end{array}$} & \multicolumn{2}{|l|}{ p } \\
\hline & \multicolumn{3}{|c|}{ Mean \pm SD/n-\% } & \multirow{2}{*}{$\begin{array}{l}\text { Mean } \\
4.00\end{array}$} & \multicolumn{3}{|c|}{ Mean $\pm S D / n-\%$} & \multicolumn{3}{|l|}{ Mean } \\
\hline & 3.85 & \pm & 0.81 & & 4.00 & \pm & 0.86 & 4.00 & 0.549 & $\mathrm{~m}$ \\
\hline Before PPV IVD (n) & 1.25 & \pm & 0.79 & 1.00 & 1.35 & \pm & 0.67 & 1.00 & 0.695 & $\mathrm{~m}$ \\
\hline Postoperative IVD (n) & 0.55 & \pm & 0.69 & 0.00 & 0.10 & \pm & 0.31 & 0.00 & 0.012 & $\mathrm{~m}$ \\
\hline
\end{tabular}

In both groups, a statistically significant improvement in BCVA developed at the first, third, sixth, ninth and twelfth months compared to the pre-PPV period. The improvement level in BCVA was more evident especially at the first and third months postoperatively in both groups $(p<0.01)$. Improvement in BCVA at the first and third months postoperatively was statistically more significant in Group 2 than Group 1 ( $p<$ 0.05) (Table 3) (Fig. 1). 
Table 3

The best corrected visual acuity (BCVA) of the groups

Group 1

(ILM non-peeled)

Mean $\pm S D / n-\%$
Group 2

(ILM peeled)

\begin{tabular}{|c|c|c|c|c|c|c|c|c|c|c|}
\hline \multirow[b]{2}{*}{ BCVA (LogMar) } & \multicolumn{3}{|c|}{ Mean $\pm S D / n-\%$} & \multirow[t]{2}{*}{ Mean } & \multicolumn{3}{|c|}{ Mean \pm SD $/ n-\%$} & \multicolumn{3}{|l|}{ Mean } \\
\hline & & & & & & & & & & \\
\hline Before PPV & 0.88 & \pm & 0.29 & 1.00 & 0.90 & \pm & 0.27 & 1.00 & 0.822 & $\mathrm{~m}$ \\
\hline Postoperative 1st month & 0.69 & \pm & 0.15 & 0.69 & 0.38 & \pm & 0.14 & 0.39 & 0.000 & $\mathrm{~m}$ \\
\hline Postoperative 3rd month & 0.52 & \pm & 0.17 & 0.52 & 0.37 & \pm & 0.14 & 0.35 & 0.004 & $\mathrm{~m}$ \\
\hline Postoperative 6th month & 0.32 & \pm & 0.15 & 0.30 & 0.24 & \pm & 0.18 & 0.15 & 0.023 & $\mathrm{~m}$ \\
\hline Postoperative 9th month & 0.25 & \pm & 0.09 & 0.22 & 0.15 & \pm & 0.07 & 0.15 & 0.000 & $\mathrm{~m}$ \\
\hline $\begin{array}{l}\text { Postoperative 12th } \\
\text { month }\end{array}$ & 0.22 & \pm & 0.09 & 0.22 & 0.14 & \pm & 0.06 & 0.15 & 0.000 & $\mathrm{~m}$ \\
\hline
\end{tabular}

\section{Discussion}

Diabetes mellitus (DM) is an important a health problem that threatening societies today. It is estimated that 463 million people have DM in 2019 and could reach 578 million by 2030 and 700 million by 2045 (20). DME is a common loss of vision in diabetic patients and develop in $7 \%$ of patients (21). Risk factors for the development of DME are generally similar to those of diabetic retinopathy (22).

The most widely accepted priority treatment for DME today is injection of intravitreal anti-vascular endothelial growth factor (anti-VEGF) drugs (23). As the availability of more user-friendly microsurgical instruments and high incision speed devices increases, there is a tendency for surgical intervention to diabetic retinopathy and DME in earlier stage. PPV surgery is thought to have positive effects on DME therapy by reducing VEGF concentration in the eye and increasing oxygenation or nutrient diffusion of the retina $(24,25)$.

In Academy, the benefit of ILM peeling for the patients undergoing PPV for DME is still a dilemma (26, 27). In terms of visual acuity, there are publications that argue ILM peeling is beneficial (28), useless (8, 11) and harmful (15) in DME. Khurieva-Sattler et al. compared ILM peeling or intravitreal triamcinolone acetonide (IVTA) injection in addition to PPV in patients with diffuse DME in a non-randomized prospective study and reported more permenant results in terms of visual and anatomical improvement 
in the group whose ILM was peeled after the 4th month (28). Figueroa et al. investigated the surgical and anatomic results of PPV in patients with diffuse nontractional DME. They compared ILM peeling and IVTA injection in patients undergoing PPV and reported that the anatomical and functional success achieved in the early period in both groups did not continue in the long term and there was no statistically significant difference between the groups (8). In a controlled clinical study, Kumar et al. compared ILM peeling or grid laser application in addition to PPV in patients with diffuse DME. Although there was no difference between the groups in the first 6 months, they reported that the decrease in foveal thickness and macular volume was statistically significantly higher in the group with ILM peeling in the following period (15). Aboutable reported in a study on patients with diffuse DME without epimacular membranes, ILM peeling reduced foveal thickness and did not improve visual acuity improvement compared to nonpeeling (11). Bahadir et al. reported in their randomized controlled study that ILM peeling did not cause a significant improvement in visual acuity compared to non-peeling in patients who underwent PPV for DME treatment (16). The results of our study indicate that ILM peeling during PPV is useful for macular function and may accelerate improvement in visual acuity. One-year results of our study showed that the improvement in BCVA in the first and third months was higher and the need of IVD implants postoperatively was lower in eyes with ILM peeling.

Clinical studies in recent years have shown that frequent anti-VEGF injection therapy in the treatment of DME patients rebust efficacy and safety (29-31). There is limited evidence today about the benefit and risk of continuous injections of anti-VEGF in eyes that have not responded adequately to anti-VEGF therapy before (32). However, it is still unclear in academy how many times anti-VEGF injection had to be made in order to talk about resistance in DME management. In our study was defined resistant DME as the minimal improvement in central retinal thickness $(<15 \%)$ to at least 4 treatments (three of which were anti-VEGF injection) in last 6 months (18). In patients with proliferative diabetic retinopathy, the risk of intraoperative and postoperative hemorrhage has been reported to be reduced with intravitreal anti-VEGF treatment 3 days before the operation (33-35). For these reasons, we also applied intravitreal anti-VEGF injection 3 days before PPV to all cases in our study.

In our study, we preferred IVD implant injection in the treatment of resistant DME. IVD implant nowadays could be used for the treatment of pathologies that may have inflammation in the pathogenesis such as central retinal vein occlusion, posterior non-infectious uveitis and macular edema due to diabetic retinopathy $(36,37)$. Inflammation could play a critical role in the pathogenesis of DME. Many studies have shown that in patients with DME, proinflammatory mediators (cytokines, chemokines, growth factors) can be found in higher concentrations in aqueous humor and vitreous gel $(38,39)$. These findings may explain the effectiveness of IVD implant with anti-inflammatory properties in the treatment of DME. There are publications in the literature reporting that IVD implant injection in eyes that had previously undergone PPV was not associated with an increased risk (39-42). There are studies report that combined application of vitrectomy and IVD implant is safe and effective in terms of anatomical and functional improvement in DME treatment $(43,44)$. We have never faced any uncontrolled increase of intraocular pressure in our patients. Castro-Navaro et al. reported that IVD implant is effective even in 
resistant cases in DME treatment (45). The results of our study also support this situation. After PPV operation IVD implant injection alone was successful in almost all cases with resistant DME.

Other than DME, ILM peeling is often applied to reduce the force of tangential traction on the retinal surface for the treatment of macular hole or pucker. In recent years, many clinical studies have been published in the literature reporting that ILM peeling might be harmful for macula. Halfter et al. showed that the absence of ILM triggered irreversibly retraction of the endfeet of the neuroepithelial cells from the inner surface of the retina and the formation of an irregularly thickened ganglion cell layer (46). In a controlled randomized study conducted by Ripandelli et al. investigated the anatomical and functional results of ILM peeling in patients with idiopathic macular pucker. At the end of the one-year follow-up period, they reported that, the mean retinal sensitivity in the central region was higher and showed faster recovery in the non-peeling group, but the absolute number of microscomas was higher in the peeling group (14). In our study, the improvement in BCVA in the first and third months in the ILM peeled group was statistically significantly higher than ILM non-peeled group. In addition, the mean IVD requirement was statistically significantly higher in the ILM non-peeled group. Our findings oppose the hypothesis that ILM peeling may damage the anatomy and function of the macula with resistant DME.

\section{LIMITATION}

This study has some limitations. Firstly, small sample size and short follow-up time can be meaningful. Second, considering 'resistant DME' as non-responding to 4 consecutive treatments alone is a controversial subject. Long-term randomized clinical trials with comprehensive outcomes are needed to evaluate the safety and effectiveness for the treatment of resistant DME.

\section{Conclusion}

Vitrectomy is beneficial in the management of resistant DME, and ILM peeling seems to be necessary and harmless for macular function and visual acuity.

\section{Declarations}

\section{Ethics approval and consent to participate}

This prospective and randomized study was approved by the Institutional Ethics Committee of University of Health Sciences, Istanbul, Turkey (Study number: 17073117-050.99-2786) and was organized and carried out in accordance with the principles and recommendations of the Helsinki Declaration. Informed consent was obtained from all patients who participated in the study

\section{Consent for publication}

Not applicable.

\section{Availability of data and materials}


The data produced and analyzed during the current study is not publicly available due to the prohibition of hospital's archive system, but could be obtained from the corresponding author upon plausible and acceptable request.

\section{Competing interests}

The authors declare that there is no conflict of interest.

\section{Funding}

The author has no financial or non-financial relationships, ownership or commercial interests with any of the materials mentioned in this article.

\section{Authors' contributions}

Ahmet Altun took part in the operations of patients, imaging, data analysis, literature research and writing the article. Fatih Atmaca, Hatice Selen Kanar, Aysu Karatay Arsan, Aynur Hacısalihoglu, Banu Kale, Kenan Sonmez, Turgay Ozay, and Ali Durdu took part in the literature search and referral of patients.

\section{Acknowledgements}

We would like to thank Aygul KARACA who meticulously carried out optical coherence tomography and fundus fluorescein angiography measurements of the patients included in the study.

\section{References}

1. Yamada E (1969): Some structural features of the fovea centralis in the human retina. Arch Ophthalmol 82: 151-159.

2. A. Almony, E. Nudleman, G. K. Shah et al., "Techniques, rationale, and outcomes of internal limiting membrane peeling," Retina, vol. 32, no. 5, pp. 877-891, 2012.

3. Yooh HS, Brooks HL Jr, Capone A Jr et al. (1996): Ultrastructural features of tissue removed during idiopathic macular hole surgery. Am J Ophthalmol 122: 67-75.

4. Christensen UC. Value of internal limiting membrane peeling in surgery for idiopathic macular hole and the correlation between function and retinal morphology. Acta Ophthalmol. 2009;87 Thesis 2:123.

5. Guan J, Cai N, Liu LM, Zhao N, Liu NN. Ranibizumab Pretreatment in Vitrectomy with Internal Limiting Membrane Peeling on Diabetic Macular Edema in Severe Proliferative Diabetic Retinopathy [published online ahead of print, 2020 Apr 30]. Diabetes Ther. 2020;10.1007/s13300-020-00822-0.

6. Bolo KA, Chang S. Broad internal limiting membrane peeling with adjunctive plasma-thrombin for repair of large macular holes: A retrospective case series [published online ahead of print, $2020 \mathrm{Apr}$ 27]. Eur J Ophthalmol. 2020;1120672120920218. 
7. Yao Y, Qu J, Dong C, et al. The impact of extent of internal limiting membrane peeling on anatomical outcomes of macular hole surgery: results of a 54-week randomized clinical trial. Acta Ophthalmol. 2019;97(3):303-312.

8. Figueroa MS, Contreras I, Noval S. Surgical and anatomical outcomes of pars plana vitrectomy for diffuse nontractional diabetic macular edema. Retina. 2008;28(3):420-426.

9. Ritter M, Sacu S, Matt G, et al. Use of systemic steroid after successful macular surgery in eyes with epiretinal membrane: a randomized, controlled clinical study. Eye (Lond). 2011;25(10):1284-1293.

10. Christensen UC, Krøyer K, Sander B, Jorgensen TM, Larsen M, la Cour M. Macular morphology and visual acuity after macular hole surgery with or without internal limiting membrane peeling. $\mathrm{Br} J$ Ophthalmol. 2010;94(1):41-47.

11. Aboutable T. Ist die Entfernung der Membrana limitans interna (ILM) immer erforderlich bei Patienten mit dem therapierefraktären diffusen diabetischen Makulaödem ohne Nachweis von epimakulären Proliferationen? [Is removal of internal limiting membrane always necessary during surgery for refractory diffuse diabetic macular edema without evident epimacular proliferation?]. Klin Monbl Augenheilkd. 2006;223(8):681-686.

12. Dillinger $P, M e s t e r ~ U$. Vitrectomy with removal of the internal limiting membrane in chronic diabetic macular oedema. Graefes Arch Clin Exp Ophthalmol. 2004;242(8):630-637.

13. Kolacny D, Parys-Vanginderdeuren R, Van Lommel A, Stalmans P. Vitrectomy with peeling of the inner limiting membrane for treating diabetic macular edema. Bull Soc Belge Ophtalmol. 2005;(296):15-23.

14. Joussen AM, Weiss C, Bauer D, Hilgers RD; TIME Study group. Triamcinolone versus inner-limiting membrane peeling in persistent diabetic macular edema (TIME study): design issues and implications. Graefes Arch Clin Exp Ophthalmol. 2007;245(12):1781-1787.

15. Kumar A, Sinha S, Azad R, Sharma YR, Vohra R. Comparative evaluation of vitrectomy and dyeenhanced ILM peel with grid laser in diffuse diabetic macular edema. Graefes Arch Clin Exp Ophthalmol. 2007;245(3):360-368.

16. Bahadir M, Ertan A, Mertoğlu O. Visual acuity comparison of vitrectomy with and without internal limiting membrane removal in the treatment of diabetic macular edema. Int Ophthalmol. 2005;26(12):3-8.

17. Ripandelli G, Scarinci F, Piaggi P, et al. Macular pucker: to peel or not to peel the internal limiting membrane? A microperimetric response. Retina. 2015;35(3):498-507.

18. Klein KA, Cleary TS, Reichel E. Effect of intravitreal aflibercept on recalcitrant diabetic macular edema. Int J Retina Vitreous. 2017 Apr 3;3:16.

19. Kumar A, Gogia V, Shah VM, Nag TC. Comparative evaluation of anatomical and functional outcomes using brilliant blue $\mathrm{G}$ versus triamcinolone assisted ILM peeling in macular hole surgery in Indian population. Graefes Arch Clin Exp Ophthalmol. 2011;249(7):987-995.

20. International Diabetes Federation Diabetes Atlas. $9^{\text {th }}$ Edition. International Diabetes Federation; 2019. http://www.idf.org/diabetesatlas. 
21. Wang Y, Lin Z, Zhai G, et al. Prevalence of and risk factors for diabetic retinopathy and diabetic macular edema in patients with early and late onset diabetes mellitus [published online ahead of print, 2020 Apr 30]. Ophthalmic Res. 2020;10.1159/000508335.

22. Lee R, Wong TY, Sabanayagam C, Epidemiology of diabetic retinopathy, diabetic macular edema and related vision loss. Eye Vis. 2015;2:17.

23. Liu Y, Cheng J, Gao Y, Qin L, Min X, Zhang M. Efficacy of switching therapy to aflibercept for patients with persistent diabetic macular edema: a systematic review and meta-analysis. Ann Transl Med. 2020;8(6):382.

24. Someya H, Takayama K, Takeuchi M, et al. Outcomes of 25-Gauge Vitrectomy for Tractional and Nontractional Diabetic Macular Edema with Proliferative Diabetic Retinopathy. J Ophthalmol. 2019;2019:5304524. Published 2019 Dec 11.

25. Venkatesh R, Bavaharan B, Kumar Yadav N. Vitrectomy in diabetic macular edema.Can J Ophthalmol. 2019;54(3):402-403.

26. Romano MR, Allegrini D, Della Guardia C, et al. Vitreous and intraretinal macular changes in diabetic macular edema with and without tractional components. Graefes Arch Clin Exp Ophthalmol. 2019;257(1):1-8.

27. Rinaldi M, dell'Omo R, Morescalchi F, et al. ILM peeling in nontractional diabetic macular edema: review and metanalysis. Int Ophthalmol. 2018;38(6):2709-2714.

28. Khurieva-Sattler E, Krause M, Löw U, et al. Pars-plana-Vitrektomie mit ILM-Peeling versus intravitreale Triamcinolon-Injektion bei diffusem diabetischem Makulaödem [Comparison of pars plana vitrectomy with ILM peeling and intravitreal triamcinolone in diffuse diabetic macular oedema]. Klin Monbl Augenheilkd. 2010;227(6):496-500.

29. Diabetic Retinopathy Clinical Research Network, Wells JA, Glassman AR, et al. Aflibercept, bevacizumab, or ranibizumab for diabetic macular edema. N Engl J Med. 2015;372(13):1193-1203.

30. Korobelnik JF, Do DV, Schmidt-Erfurth U, et al. Intravitreal aflibercept for diabetic macular edema. Ophthalmology. 2014;121(11):2247-2254.

31. Mitchell P. Three-year safety and efficacy of ranibizumab in patients with visual impairment due to diabetic macular edema: The RESTORE Extension Study. Abstract presented at: American Academy of Ophthalmology Annual Meeting; 2012 Nov 12; Chicago IL. 2017.

32. Gonzalez VH, Campbell J, Holekamp NM, et al. Early and long-term responses to anti-vascular endothelial growth factor therapy in diabetic macular edema: analysis of protocol I data. Am J Ophthalmol. 2016;172:72-79.

33. Arevalo JF, Lasave AF, Wu L, et al.; Pan-American Collaborative Retina Study G. Intravitreal bevacizumab for proliferative diabetic retinopathy: results From the Pan-American Collaborative Retina Study Group (PACORES) at 24 months of follow-up. Retina. 2016

34. Castillo J, Aleman I, Rush SW, Rush RB. Preoperative bevacizumab administration in proliferative diabetic retinopathy patients undergoing vitrectomy: a randomized and controlled trial comparing interval variation. Am J Ophthalmol. 2017;183:1-10. 
35. Arevalo JF, Liu TYA; Pan-American Collaborative Retina Study G: Intravitreal Bevacizumab in Diabetic Retinopathy. Recommendations from the Pan-American Collaborative Retina Study Group (PACORES): the 2016 Knobloch lecture. Asia Pac J Ophthalmol (Phila). 2018;7(1):36-39.

36. Kaya M, Kocak N, Ozturk T, Bolluk V, Ayhan Z, Kaynak S. Intravitreal ranibizumab and dexamethasone implant injections as primary treatment of diabetic macular edema: simultaneously double protocol [published online ahead of print, 2020 May 12]. Eye (Lond). 2020;10.1038/s41433020-0949-2.

37. Clinical Review Report: Dexamethasone (Ozurdex): (Allergan Inc.). Ottawa (ON): Canadian Agency for Drugs and Technologies in Health; 2018.

38. Noma H, Mimura T, Yasuda K, Shimura M. Role of inflammation in diabetic macular edema. Ophthalmologica. 2014;232(3):127-135.

39. Yoshimura $\mathrm{T}$, Sonoda $\mathrm{KH}$, Sugahara $\mathrm{M}$, et al. Comprehensive analysis of inflammatory immune mediators in vitreoretinal diseases. PLoS One. 2009;4(12):e8158.

40. Dexamethasone intravitreal implant in vitrectomized versus nonvitrectomized eyes for treatment of patients with persistent diabetic macular edema. Medeiros MD, Alkabes M, Navarro R, Garcia-Arumí J, Mateo C, Corcóstegui B J Ocul Pharmacol Ther. 2014 Nov; 30(9):709-16.

41. Zheng A, Chin EK, Almeida DR, Tsang SH, Mahajan VB. Combined Vitrectomy And Intravitreal Dexamethasone (Ozurdex) Sustained-Release Implant. Retina. 2016;36(11):2087-2092.

42. Hostovsky A, Muni RH, Eng KT, Mulhall D, Leung C, Kertes PJ. Intraoperative Dexamethasone Intravitreal Implant (Ozurdex) in Vitrectomy Surgery for Epiretinal Membrane [published online ahead of print, 2019 Dec 10]. Curr Eye Res. 2019;1-5.

43. Kim KT, Jang JW, Kang SW, Chae JB, Cho K, Bae K. Vitrectomy Combined with Intraoperative Dexamethasone Implant for the Management of Refractory Diabetic Macular Edema. Korean $\mathrm{J}$ Ophthalmol. 2019;33(3):249-258.

44. Jung YH, Lee Y. Efficacy of vitrectomy combined with an intraoperative dexamethasone implant in refractory diabetic macular edema. Acta Diabetol. 2019;56(6):691-696.

45. Castro-Navarro V, Cervera-Taulet E, Navarro-Palop C, Monferrer-Adsuara C, Hernández-Bel L, MonteroHernández J. Intravitreal dexamethasone implant Ozurdex ${ }^{\circledR}$ in naïve and refractory patients with different subtypes of diabetic macular edema. BMC Ophthalmol. 2019;19(1):15.

46. Halfter W., Dong S., Balasubramani M., and Bier M. E., "Temporary disruption of the retinal basal lamina and its effect on retinal histogenesis," Developmental Biology, vol. 238, no. 1, pp. 79-96, 2001.

\section{Figures}




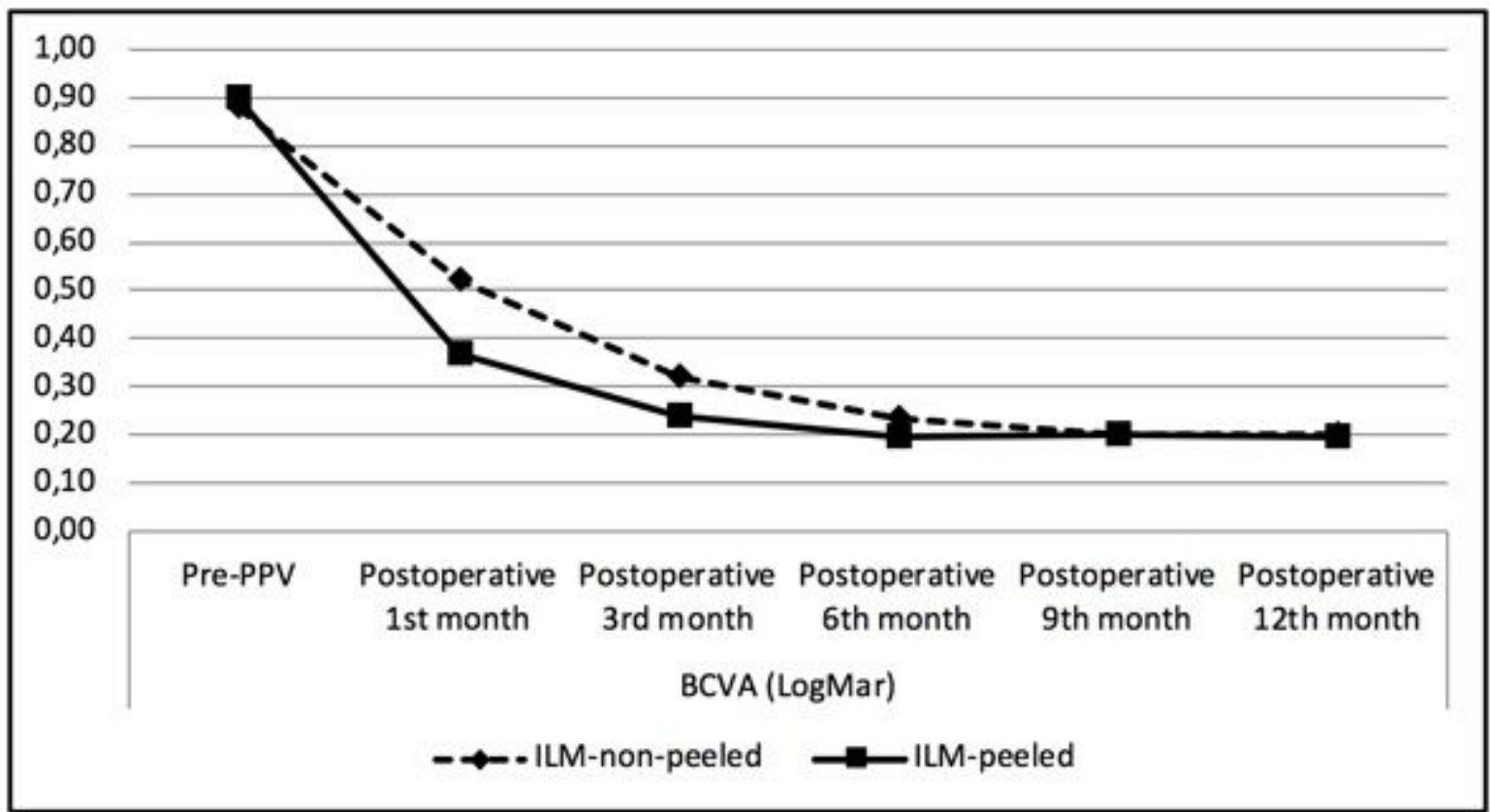

Figure 1

Change in the best corrected visual acuity (BCVA) of the groups

\section{Supplementary Files}

This is a list of supplementary files associated with this preprint. Click to download.

- Table2.docx

- Table1.docx

- Table3.docx 